\title{
Evaluation of 3K3A-Activated Protein C to Treat Neonatal Hypoxic Ischemic Brain Injury in the Spiny Mouse
}

\author{
Stacey J. Ellery ${ }^{1,2}$ (D) Madeleine G. Goss ${ }^{1} \cdot$ Nadine Brew $^{1} \cdot$ Hayley Dickinson $^{1,2} \cdot$ Nadia Hale $^{1} \cdot$ Domenic A. LaRosa $^{1,2,3} \cdot$ \\ David W. Walker $^{1,2,4}$. Flora Y. Wong ${ }^{1,5,6}$
}

Published online: 17 September 2018

(C) The American Society for Experimental NeuroTherapeutics, Inc. 2018

\begin{abstract}
Neonatal hypoxic ischemic encephalopathy (HIE) resulting from intrapartum asphyxia is a global problem that causes severe disabilities and up to 1 million deaths annually. A variant form of activated protein $\mathrm{C}, 3 \mathrm{~K} 3 \mathrm{~A}-\mathrm{APC}$, has cytoprotective properties that attenuate brain injury in models of adult stroke. In this study, we compared the ability of 3K3A-APC and APC (wild-type (wt)) to attenuate neonatal brain injury, using the spiny mouse (Acomys cahirinus) model of intrapartum asphyxia. Pups were delivered at 38 days of gestation (term $=39$ days), with an intrapartum hypoxic insult of $7.5 \mathrm{~min}$ (intrapartum asphyxia cohort), or immediate removal from the uterus (control cohort). After $1 \mathrm{~h}$, pups received a subcutaneous injection of 3K3A-APC or wild-type APC (wtAPC) at $7 \mathrm{mg} / \mathrm{kg}$, or vehicle (saline). At $24 \mathrm{~h}$ of age, pups were killed and brain tissue was collected for measurement of inflammation and cell death using RT-qPCR and histopathology. Intrapartum asphyxia increased weight loss, inflammation, and apoptosis/necrosis in the newborn brain. 3K3A-APC administration maintained body weight and ameliorated an asphyxia-induced increase of $T G F \beta 1$ messenger RNA expression in the cerebral cortex, immune cell aggregation in the corpus callosum, and cell death in the deep gray matter and hippocampus. In the cortex, 3K3A-APC appeared to exacerbate the immune response to the hypoxic ischemic insult. While wtAPC reduced cell death in the corpus callosum and hippocampus following intrapartum asphyxia, it increased markers of neuro-inflammation and cell death in control pups. These findings suggest $3 \mathrm{~K} 3 \mathrm{~A}-\mathrm{APC}$ administration may be a useful therapy to reduce cell death and neonatal brain injury associated with HIE.
\end{abstract}

Keywords Birth $\cdot$ Intrapartum asphyxia $\cdot$ Brain injury $\cdot$ Neuro-inflammation $\cdot$ Apoptosis

Stacey J. Ellery

stacey.ellery@hudson.org.au

1 The Ritchie Centre, Hudson Institute of Medical Research, 27-31 Wright St, Clayton, Melbourne 3168, Australia

2 Department of Obstetrics and Gynaecology, Monash University, Clayton, Australia

3 Women and Infants Hospital, Alpert Medical School, Brown University, Providence, RI, USA

4 School of Health and Biomedical Sciences, RMIT University, Melbourne, Australia

5 Department of Paediatrics, Monash University, Clayton, Australia

6 Monash Newborn, Monash Medical Centre, Clayton, Melbourne, Australia

\section{Introduction}

Each year, approximately 4 million neonates experience a period of acute hypoxia-ischemia during birth [1], often leading to the clinical presentation of hypoxic ischemic encephalopathy (HIE), and a range of adverse outcomes, including neurological disability and even death [2]. At a mechanistic level, the hypoxic ischemic (HI) insult initiates a cascade of cellular responses that lead to oxidative stress, neural excitotoxicity, and neuro-inflammation in the neonatal brain, which contribute to irreversible cell damage, apoptosis/necrosis, and permanent neurological deficits [3].

Activated protein C (APC) is a vitamin K-dependent glycoprotein derived from the protein $\mathrm{C}$ zymogen produced by the liver which, through interaction with thrombomodulin and/or endothelial protein $\mathrm{C}$ receptor (EPCR), has both 
anticoagulant and cytoprotective properties [4]. APC has shown promise for treatment of a number of conditions, including adult ischemic stroke [5] and thrombosis [6]. APC has been shown to downregulate NFKB-driven inflammatory cytokine release from leukocytes and endothelial cells [7], downregulate pro-apoptotic proteins Bax and p53 [8], and protect the endothelial barrier [9-11]. Experimental studies examining the neuroprotective effects of APC in neonatal HIE have shown that APC treatment reduced the level of apoptosis in the dentate gyrus and cornu ammonis CA1, CA2, and CA3 hippocampal regions compared to the vehicle-treated group [12] and ameliorated systemic inflammation [13]. However, the anticoagulant properties of APC increase the risk of bleeding and intracranial hemorrhage in neonates, as shown in a subgroup of children $<60$ days of age with sepsis who were treated with APC [14]. To utilize the neuroprotective properties of APC and minimize the associated risk of bleeding, a variant form of APC has been genetically engineered-3 3 3A-APC - differing from wild-type APC (wtAPC) through the replacement of 3 lysine residues with 3 alanine residues (K191A-K192A-K193A). This structural change significantly decreases, by 80 to $90 \%$, the anticoagulant properties of APC while preserving cytoprotective actions [15]. This variant form of APC exhibited superior neuroprotection to wtAPC in an adult mouse stroke model [16] and is currently being trialled as a treatment for adult ischemic stroke (ClinicalTrials.gov Identifier: NCT02222714). However, there have been no experimental studies investigating the use of $3 \mathrm{~K} 3 \mathrm{~A}-\mathrm{APC}$ to treat neonatal hypoxic ischemic brain injury.

Using a well-validated model of intrapartum asphyxia in the spiny mouse [17-22], we investigated the effects of $3 \mathrm{~K} 3 \mathrm{~A}-\mathrm{APC}$ treatment on the neuropathology that follows brief asphyxia, in comparison with vehicle (saline) or wtAPC treatments. Specifically, our aim was to assess the cerebral effects of 3K3A-APC in both the gray and white matter by examining markers of neuro-inflammation and cell death. We hypothesized that $3 \mathrm{~K} 3 \mathrm{~A}-\mathrm{APC}$ would display the same neuroprotective affects in the hypoxic ischemic neonatal brain as have been previously described for wtAPC, on assessment of neuropathology and gene expression at 24-h postnatal age.

\section{Methods}

\section{Ethical Approval}

Ethical approval was granted by the Monash Medical Centre A (MMC-A) Animal Ethics Committee (AEC; AEC Project Number: 2011/49) for all procedures and conditions utilized in this project.

\section{Housing Facility and Animal Care}

Spiny mice (Acomys cahirinus) were sourced from the Monash Medical Centre colony. These spiny mice were bred and housed as previously described [23].

Intrapartum asphyxia was induced at 38 days of gestation (term at 39 days) as previously described [17-22]. Briefly, pregnant dams were killed via cervical dislocation. Immediately, a midline abdominal incision was made to access the uterus, which was then ligated at the cervix and top of the uterine horns. The entire uterus containing the unborn pups was removed and placed in a $37{ }^{\circ} \mathrm{C}$ saline bath for $7.5 \mathrm{~min}$ to induce a hypoxic insult ( $n=13$ dams, $n=33$ pups). Following this period of progressive hypoxia in utero, the uterus was opened on a heated pad $\left(40^{\circ} \mathrm{C}\right)$, and the pups were quickly removed and then resuscitated by clearing the airways and rubbing and stimulating the chest and abdominal regions with warm, moistened cotton tips. Pups assigned to the control group ( $n=9$ dams, $n=19$ pups) were delivered via cesarean (c) section and immediately resuscitated (time to deliver all pups from the uterus, $43.5 \pm 8 \mathrm{~s}$ ).

At $1 \mathrm{~h}$ after delivery, surviving pups from both asphyxia and c-section deliveries received a subcutaneous injection of either $7 \mathrm{mg} / \mathrm{kg}$ of human recombinant wtAPC (Xigris; Eli Lily, Indianapolis, IN) or $7 \mathrm{mg} / \mathrm{kg}$ of human recombinant $3 \mathrm{~K} 3 \mathrm{~A}-\mathrm{APC}$ (a gift from $\mathrm{ZZ}$ Biotech, Rochester, NY; Lot No.: FILZB1-03) or an equivalent volume $(7 \mu \mathrm{L} / \mathrm{g}$ of body weight $)$ of sterile saline. The APC dose was calculated from the human dose of $576 \mu \mathrm{g} / \mathrm{kg} /$ day [24], with adjustment for species differences [25]. After administration of the drug or saline, the experimental pups were cross-fostered to a lactating dam that had given birth in the preceding $1 \mathrm{~h}$ to $12 \mathrm{~h}$.

At 24-h postnatal age, pups were weighed and then sacrificed via cervical dislocation. Brain weight was recorded, before the right cerebral hemisphere was dissected to obtain a sample of the cerebral cortex and deep gray matter (DGM), which were immediately snap-frozen in liquid $\mathrm{N}_{2}$ and stored at $-80{ }^{\circ} \mathrm{C}$ for subsequent molecular analysis. The left hemisphere was left intact and immersion fixed in $10 \%$ buffered formalin for 2 days, before being processed to paraffin for histological examination.

\section{Gene Expression}

Real-time quantitative polymerase chain reaction (RT-qPCR) was used to determine the messenger RNA (mRNA) expression of a suite of genes associated with inflammation $(N F \kappa B$, $T N F \alpha, I L-6, I L-1 \beta$, and $I L-4)$, neuronal populations (S100B and ENO2), and apoptosis (Casp3, P53, HSP70, Bax:Bcl2, and $T G F \beta 1$ ) in cortical and DGM regions obtained from the 24-h-old pups delivered by c-section or after intrapartum asphyxia. Cyclophilin A (PPIA) and 18S ribosomal 1 (RN18S1) 
were used as housekeeping genes. Primer sequences are shown in Table 1. Total RNA was extracted from both the frozen cortex and DGM tissues using RNeasy kits according to the manufacturer's protocol (Qiagen, Glen Forrest, Australia) and reverse transcribed to form cDNA according to the manufacturer's protocol (Promega, Madison, WI).

RT-qPCR was carried out using SYBR Green PCR Master Mix (Applied Biosystems, Carlsbad, CA) and Stratagene Mx3000P (Thermofisher Scientific, Waltham, MA) thermal cycler system. Cycling conditions were as follows: $95^{\circ} \mathrm{C}$ for $10 \mathrm{~min} ; 95^{\circ} \mathrm{C}$ for $15 \mathrm{~s}, 60^{\circ} \mathrm{C}$ for $1 \mathrm{~min} \times 40$ cycles; and $95^{\circ} \mathrm{C}$ for $5 \mathrm{~s}, 60^{\circ} \mathrm{C}$ for $15 \mathrm{~s}, 95^{\circ} \mathrm{C}$ for $15 \mathrm{~s} \times 40$ cycles. Data from qPCR was analyzed according to the ${ }^{\Delta \Delta} \mathrm{CT}$ method [26], and results are expressed relative to values obtained for the salinetreated, c-section control pups.

\section{Neuropathology}

Tissue Preparation Sagittal sections of $5 \mu \mathrm{m}$ thickness were cut using a microtome and mounted on Superfrost ${ }^{\mathrm{TM}}$ glass slides (Menzel-Gläser, distributed by Lomb Scientific Pty Ltd., Australia). Slides were left in a $37{ }^{\circ} \mathrm{C}$ oven overnight to ensure adhesion of the sections.

Hematoxylin and Eosin Brain sections were first stained with hematoxylin and eosin (H\&E) to discern the gross morphology and anatomical location as compared to defined levels in a mouse brain atlas [27]. The brain regions included in subsequent analysis were the corpus callosum, parietal cortex (cortex layers 2-6), DGM (which consists of the caudate putamen and thalamus), and hippocampus, selected topographically using published nomenclature for the mouse brain at the

Table 1 Primer sequences

\begin{tabular}{|c|c|c|}
\hline & Forward primer sequence $\left(5^{\prime}-3^{\prime}\right)$ & Reverse primer sequence $\left(3^{\prime}-5^{\prime}\right)$ \\
\hline \multirow[t]{8}{*}{ Pro-inflammatory } & \multicolumn{2}{|c|}{ Nuclear factor kappa-light-chain enhancer of activated B cells $(N F \kappa B)$} \\
\hline & TGAGGGATCTGCTGGAAGTC & CCAAGTGCAGAGGTGTCTGA \\
\hline & \multicolumn{2}{|l|}{ Tumor necrosis factor alpha $(T N F \alpha)$} \\
\hline & CGGCATGGACCTCAAAGACA & TGGGTGAGGAGGACGTAGTT \\
\hline & \multicolumn{2}{|l|}{ Interleukin-6 (IL-6) } \\
\hline & ACAGATTGGCACTCTTTGGCA & ACGAATGGCTGAGGACCAAG \\
\hline & \multicolumn{2}{|l|}{ Interleukin-1 beta $(I L-1 \beta)$} \\
\hline & TTCTGCCTGGGAGGTACTGA & GAGAGCGTGGATCCCAAACA \\
\hline \multirow{4}{*}{$\begin{array}{l}\text { Neuronal population } \\
\text { markers }\end{array}$} & \multicolumn{2}{|l|}{ S100 Calcium binding protein $(S 100 B)$} \\
\hline & TGGTGGTCTGCAGCATTGAT & CCATCCCAAGGGCTGCTTTA \\
\hline & \multicolumn{2}{|l|}{ Neuron-specific enolase (ENO2) } \\
\hline & TGAGGGATCTGCTGGAAGTC & CCAAGTGCAGAGGTGTCTGA \\
\hline \multirow[t]{2}{*}{ Anti-inflammatory } & \multicolumn{2}{|l|}{ Interleukin-4 $(I L-4)$} \\
\hline & CCCCTCAGTAAAACCCTCCA & CGGTAAAGAAAGCTGTCGGC \\
\hline \multirow[t]{12}{*}{ Pro-apoptotic } & \multicolumn{2}{|l|}{ Caspase 3 (Casp3) } \\
\hline & CGCCATGCTGAAACTGTACG & ATGAAAGGTGGAGTCGAGCG \\
\hline & \multicolumn{2}{|l|}{ Tumor protein $(P 53)$} \\
\hline & AGGACCTTCCAAGTACACGC & TCCCTGGCTGAGGTTTTGTT \\
\hline & \multicolumn{2}{|l|}{ Heat shock protein $70(H S P 70)$} \\
\hline & GAGGCAGAGAGGTACAAGGC & TCACCGCGCTCTTCATGTTA \\
\hline & \multicolumn{2}{|l|}{ Bcl2-associated X protein $(B A X)$} \\
\hline & TTGCTGATGGCAACTTCAACTG & CTTTAGTGCACAGGGCCTTGAG \\
\hline & \multicolumn{2}{|l|}{ B-cell CLL/lymphoma 2 (BCL2) } \\
\hline & TGGTACCTGCAGCTTCTTTC & TCCCTTTGGCAGTAAATAGC \\
\hline & \multicolumn{2}{|l|}{ Transforming growth factor beta $1(T G F 1 \beta)$} \\
\hline & CCAGGAACTCCACAGCTCAAG & ACACAGCAGTTCTTCTCCGTG \\
\hline \multirow[t]{4}{*}{ Housekeeping genes } & \multicolumn{2}{|l|}{ RN18S1 (RNA, 18S ribosomal 1) } \\
\hline & ACACGGACAGGATTGACAGA & CAAATCGCTCCACCACCAACTAA \\
\hline & \multicolumn{2}{|c|}{ PPIA (peptidylprolyl isomerase A (cyclophilin A)) } \\
\hline & CTGATGGCGAGCCCTTG & TCTCCTGTCTTTGGAACTTTGTC \\
\hline
\end{tabular}

Oligonucleotide primer sequences were used for RT-qPCR 
mid-sagittal and mid-striatal level (corresponding to the mouse brain atlas of sagittal sections at level 16 [27]). The $\mathrm{H} \& \mathrm{E}$ stain was also used to make observations of intracerebral hemorrhage.

Immunohistochemistry Microglia were identified using rabbit anti-ionized calcium-binding adaptor molecule (Iba-1) (1:500; 019-19741, Wako Laboratory Chemicals, Japan), and activated microglia were identified using anti-CD11 $\beta$ antibody (CD11 $)$ (1:1000; AB62817, Abcam, Australia). Astrocytes were identified using monoclonal anti-glial fibrillary acidic protein (GFAP) antibody (1:400; G3893, Sigma, Australia).

All sections were deparaffinized, and antigen retrieval was performed by pretreating with citrate buffer $(\mathrm{pH} \mathrm{6.0)}$ ) for $7 \mathrm{~min}$ in the microwave oven. Endogenous peroxidase activity was blocked by incubation with $3 \%$ hydrogen peroxidase. Nonspecific binding was blocked by incubation in $10 \%$ goat serum in PBS for sections incubated with the Iba- 1 and GFAP antibodies and by incubation in CAS-Block Histochemical Reagent (008120; Thermo Fisher Scientific, Australia) for sections incubated with the $\mathrm{CD} 11 \beta$ antibody.

Sections were subsequently incubated overnight with the primary antibodies at $4{ }^{\circ} \mathrm{C}$. Note, a slide with primary antibody omission was used as a negative control for each run of slides. All sections were incubated in appropriately matched secondary antibodies (1:200) for $60 \mathrm{~min}$ and reacted using avidin-biotin peroxidase complex kit (VEPK6100; Vector Laboratories, Burlingame, CA). Reactive product was visualized using 3,3'-diaminobenzidine (8980681; MP Biomedicals, Santa Ana, CA) according to the manufacturer's instructions.

TUNEL Assays To identify cell death (apoptotic and necrotic), paraffin sections were reacted with the DeadEnd Colorimetric TUNEL System that labels terminal deoxynucleotidyl transferase dUTP, according to the manufacturer's instructions (G7130; Promega, Australia).

Image Analysis All sections were digitally scanned (Image Scope; Aperio Technologies, Inc.) and analyzed at $\times 400$ magnification by an observer blinded to the experimental groups. Two mid-sagittal sections $10 \mu \mathrm{m}$ apart were examined per animal for each selected brain region. Iba-1-, GFAP-, CD11 $\beta$-, and TUNEL-positive cells were manually counted in 12 fields for the parietal cortex $(100 \mu \mathrm{m} \times 100 \mu \mathrm{m})$. The depth of the cortex from layer 2 to layer 6 was measured and then divided evenly into upper and lower levels: 6 fields were randomly placed in each level and counted. For the hippocampus, 24 fields $(50 \mu \mathrm{m} \times 50 \mu \mathrm{m})$ were randomly plotted in each brain region of interest in each tissue section. The results were expressed as areal density (cells $/ \mathrm{mm}^{2}$ ). For the corpus callosum and DGM (thalamus and caudate putamen), the entire region of interest was outlined, its area was calculated, and all positive cells in the region were counted. In addition to counting the total number of microglia, the number of activated microglia was identified as Iba-1-positive cells with an amoeboid morphology $[28,29]$, usually with a large cell body of round or irregular shape, with short, thick branching processes or devoid of branching processes, and was expressed as the number of cells/square millimeter [28].

\section{Statistical Analysis}

All data were assessed for normal distribution. A 2-way ANOVA was used for all statistical comparisons [30]. The 2 independent variables analyzed were birth mode $\left(P_{\text {Birth }}\right.$; csection or intrapartum asphyxia) and drug administration ( $P_{\text {Treat }}$; saline, wtAPC, or 3K3A-APC). When a significant interaction $\left(P_{\mathrm{Int}}\right)$ between birth mode $\left(P_{\mathrm{Birth}}\right)$ and drug administration $\left(P_{\text {Treat }}\right)$ was identified, a Tukey post hoc analysis was conducted to identify which combination(s) of birth type and drug administration was responsible for the significant difference(s). All statistical comparisons were performed with GraphPad Prism 6 statistical software. Data are presented as mean \pm standard error of the mean (SEM), with statistical significance accepted when $P$ was $<0.05$.

\section{Results}

\section{General Characteristics}

A summary of cohort characteristics for this study is reported in Table 2. There were no differences in sex ratios between groups. Intrapartum asphyxia produced a moderate mortality rate, with $69 \%$ of spiny mouse pups experiencing the hypoxic insult surviving to 24-h postnatal age; there were no sex differences in survival rates (males, $70 \%$; females, $68 \%$ ). There was a significant difference in the average body weight of pups delivered by c-section or intrapartum asphyxia $\left(P_{\text {Birth }}\right.$ $<0.01$ ), with control pups being heavier than asphyxiated pups, despite random allocation of pregnant spiny mice to the different modes of delivery, and consistent litter sizes between cohorts. The difference in body weight between groups was still evident $24 \mathrm{~h}$ after delivery. At postmortem, it was evident that intrapartum asphyxia had resulted in a significant decrease of body weight of pups in all the treatment groups, compared to those delivered by c-section $\left(P_{\text {Birth }}<0.01\right)$. All pups had lost weight during the first $24 \mathrm{~h}$, but the greatest loss occurred in the asphyxia group treated with wtAPC, in which the weight loss was $17.23 \%$ (Table 2). Pups treated with $3 \mathrm{~K} 3 \mathrm{~A}-\mathrm{APC}$ showed a weight loss of $6.40 \%$, which was comparable to that observed in the c-section-saline pups (4.02\%). The smallest relative loss of body weight $(3.23 \%)$ occurred in 
Table 2 Cohort characteristics

\begin{tabular}{|c|c|c|c|c|c|c|c|c|c|}
\hline & \multicolumn{2}{|l|}{ Saline } & \multicolumn{2}{|l|}{ wtAPC } & \multicolumn{2}{|l|}{ 3K $3 \mathrm{~A}-\mathrm{APC}$} & \multicolumn{3}{|l|}{ Statistics } \\
\hline & $\mathrm{C}$-section & Asphyxia & C-section & Asphyxia & $\mathrm{C}$-section & Asphyxia & $P_{\text {Birth }}$ & $P_{\text {Treat }}$ & $P_{\text {Int }}$ \\
\hline Number of pups & 6 & 9 & 6 & 7 & 7 & 7 & & & \\
\hline $\operatorname{Sex}(M ; F)$ & $4 ; 2$ & $3 ; 6$ & $3 ; 3$ & $3 ; 4$ & $3 ; 4$ & $4 ; 3$ & & & \\
\hline Birth weight (g) & $5.43 \pm 0.70$ & $4.73 \pm 0.57$ & $5.24 \pm 0.22$ & $4.75 \pm 0.60$ & $5.18 \pm 0.30$ & $4.76 \pm 0.60$ & $<0.01$ & NS & NS \\
\hline Postmortem BW (g) & $5.22 \pm 0.69$ & $4.30 \pm 0.44$ & $4.91 \pm 0.30$ & $3.93 \pm 0.93$ & $5.01 \pm 0.29$ & $4.50 \pm 0.95$ & $<0.001$ & NS & NS \\
\hline $24 \mathrm{~h}$ weight loss (\%) & $4.02 \pm 3.04$ & $11.68 \pm 4.76$ & $6.34 \pm 4.88$ & $17.23 \pm 9.21$ & $3.23 \pm 3.39$ & $6.40 \pm 9.23$ & $<0.05$ & $<0.001$ & NS \\
\hline Brain weight (mg) & $488.3 \pm 36.9$ & $432.6 \pm 30.6$ & $447.5 \pm 33.1$ & $411.9 \pm 37.3$ & $462.5 \pm 37.7$ & $452.1 \pm 44.8$ & $<0.001$ & NS & NS \\
\hline Brain/body weight & $0.09 \pm 0.00$ & $0.10 \pm 0.01$ & $0.09 \pm 0.00$ & $0.11 \pm 0.15$ & $0.09 \pm 0.00$ & $0.10 \pm 0.02$ & $<0.01$ & NS & NS \\
\hline
\end{tabular}

Values are mean \pm SEM; $n=6-9$ /group. Statistical analysis, 2 -way ANOVA with the 2 independent variables as birth mode $\left(P_{\text {Birth }}\right.$; control c-section vs intrapartum asphyxia) and drug administration ( $P_{\text {Treat }}$; saline, wtAPC, or 3K3A-APC). Significance, $P \leq 0.05$

the pups delivered by c-section and who received the $3 \mathrm{~K} 3 \mathrm{~A}-$ APC treatment (Table 2).

Total brain weight was also significantly lower after intrapartum asphyxia compared to c-section-delivered offspring $\left(P_{\text {Birth }}<0.001\right)$. Of note, the lowest brain weights were recorded in the asphyxiated pups who had received the wtAPC treatment- $15 \%$ less than the c-section controls. Despite the overall reductions of body weight and brain weight of the asphyxiated pups, there was a significant increase in the brain/body weight ratio in these offspring at postmortem $\left(P_{\text {Birth }}<0.001\right)$, and this was not different between the saline, wtAPC, and 3K3A-APC-treated groups (Table 2).

\section{Gene Expression}

mRNA expression was assessed in the cortical and DGM regions of the brain, $24 \mathrm{~h}$ after intrapartum asphyxia.

Pro-inflammatory $N F \kappa B$ mRNA expression, a protranscriptional factor for inflammatory cytokines, was upregulated following intrapartum asphyxia in the cortical samples (Table 3; $P_{\text {Birth }}<0.01$ ). This response was most pronounced in the asphyxiated pups administered 3K3A-APC $\left(P_{\text {Int }}<\right.$ $0.01)$. $T N F \alpha$ mRNA expression was not changed by intrapartum asphyxia alone but was also significantly increased in the asphyxiated pups treated with $3 \mathrm{~K} 3 \mathrm{~A}-\mathrm{APC}$ (Table $3 ; P_{\text {Int }}<0.05$ ). Intrapartum asphyxia alone had no effect on $I L-6$ mRNA; however, a significant interaction was observed, with expression being upregulated in the asphyxiated pups administered saline and 3K3A-APC, but not after intrapartum asphyxia in the pups treated with wtAPC $\left(P_{\mathrm{Int}}<\right.$ $0.01)$. No changes in $I L-1 \beta$ were observed between groups. In the DGM, $N F \kappa B$ mRNA expression was upregulated following intrapartum asphyxia when compared to c-section-saline controls, irrespective of drug administration $\left(P_{\text {Birth }}<0.001\right)$.
No changes in $T N F \alpha, I L-6$, or $I L-1 \beta$ mRNA expression were observed between groups (Table 4).

Neuronal Population Markers Intrapartum asphyxia led to a downregulation of $S 100 \mathrm{~B}$ and $E N O 2$ mRNA expression in cortical tissue (Table 3; $P_{\text {Birth }}<0.01$ and $P_{\text {Birth }}<0.05$, respectively), an outcome not affected by administration of wtAPC or 3K3A-APC. No changes for these markers were observed in the DGM (Table 4).

Anti-inflammatory Expression of $I L-4$ mRNA in the cortex was upregulated after intrapartum asphyxia in pups administered either saline or $3 \mathrm{~K} 3 \mathrm{~A}-\mathrm{APC}\left(P_{\mathrm{Birth}}<0.01\right)$, but no change in expression was observed in the asphyxiated pups treated with wtAPC (Table 3; $P_{\mathrm{Int}}<0.05$ ). Mode of birth or drug administration had no effect on $I L-4$ mRNA expression in the DGM (Table 4).

Apoptosis In the cortex, there were no differences in the mRNA expression of pro-apoptotic markers Casp3, P53, and Bax:Bcl2 between groups (Table 3). HSP70 mRNA expression was increased with intrapartum asphyxia, irrespective of the treatment at $1 \mathrm{~h}\left(P_{\text {Birth }}<0.01\right) . T G F \beta 1$ mRNA expression was upregulated following intrapartum asphyxia when saline or wtAPC was administered but downregulated in the asphyxiated pups treated with $3 \mathrm{~K} 3 \mathrm{~A}-\mathrm{APC}\left(P_{\mathrm{Int}}<0.01\right)$. In the DGM, P53 mRNA expression was increased with birth asphyxia compared to csection-saline pups, irrespective of drug administration (Table 4; $P_{\text {Birth }}<0.05$ ). Casp 3 mRNA expression was not altered directly by intrapartum asphyxia, but expression was significantly lower in the asphyxia group given $3 \mathrm{~K} 3 \mathrm{~A}-\mathrm{APC}$ compared to the intrapartum asphyxia-saline cohort, as well as the c-section controls $\left(P_{\text {Treat }}<0.05, P_{\text {Int }}<0.001\right)$. No significant differences were observed between groups for the other pro-apoptotic markers assessed (HSP70, Bax:Bcl2, $T G F \beta 1$ ) (Table 4). 
Table 3 Cortex RT-qPCR analysis

\begin{tabular}{|c|c|c|c|c|c|c|c|c|c|}
\hline & \multicolumn{2}{|l|}{ Saline } & \multicolumn{2}{|l|}{ wtAPC } & \multicolumn{2}{|l|}{ 3K3A-APC } & \multicolumn{3}{|c|}{ Statistics } \\
\hline & C-section & Asphyxia & C-section & Asphyxia & C-section & Asphyxia & $P_{\text {Birth }}$ & $P_{\text {Treat }}$ & $P_{\text {Int }}$ \\
\hline \multicolumn{10}{|c|}{ Pro-inflammatory } \\
\hline$N F \kappa B$ & $1.00 \pm 0.33^{\mathrm{a}}$ & $2.00 \pm 0.20$ & $1.64 \pm 0.36$ & $1.22 \pm 0.24$ & $0.85 \pm 0.07^{\mathrm{b}}$ & $2.54 \pm 0.39^{\mathrm{a}, \mathrm{b}}$ & $<0.01$ & NS & $<0.01$ \\
\hline$T N F \alpha$ & $1.00 \pm 0.06$ & $1.05 \pm 0.12$ & $0.95 \pm 0.16$ & $1.06 \pm 0.16$ & $0.82 \pm 0.07^{\mathrm{a}}$ & $1.62 \pm 0.23^{\mathrm{a}}$ & $<0.05$ & NS & $<0.05$ \\
\hline$I L-6$ & $1.00 \pm 0.12$ & $1.42 \pm 0.04^{\mathrm{a}}$ & $1.19 \pm 0.10$ & $0.92 \pm 0.18^{\mathrm{a}, \mathrm{b}}$ & $1.04 \pm 0.15$ & $1.54 \pm 0.14^{\mathrm{b}}$ & NS & NS & $<0.01$ \\
\hline$I L-1 \beta$ & $1.00 \pm 0.09$ & $0.98 \pm 0.10$ & $1.08 \pm 0.08$ & $1.03 \pm 0.16$ & $1.13 \pm 0.07$ & $1.06 \pm 0.13$ & NS & NS & NS \\
\hline \multicolumn{10}{|c|}{ Neuronal population markers } \\
\hline$S 100 B$ & $1.00 \pm 0.06$ & $0.93 \pm 0.18$ & $1.88 \pm 0.34$ & $0.80 \pm 0.18$ & $1.44 \pm 0.34$ & $1.16 \pm 0.42$ & $<0.01$ & NS & NS \\
\hline ENO2 & $1.00 \pm 0.23$ & $0.67 \pm 0.10$ & $0.72 \pm 0.11$ & $0.67 \pm 0.18$ & $0.91 \pm 0.06$ & $0.73 \pm 0.09$ & $<0.05$ & NS & NS \\
\hline \multicolumn{10}{|c|}{ Anti-inflammatory } \\
\hline$I L-4$ & $1.00 \pm 0.10$ & $1.43 \pm 0.14^{\mathrm{a}}$ & $0.92 \pm 0.15$ & $0.86 \pm 0.16$ & $0.71 \pm 0.12^{\mathrm{a}, \mathrm{b}}$ & $1.34 \pm 0.10^{\mathrm{b}}$ & $<0.01$ & NS & $<0.05$ \\
\hline \multicolumn{10}{|l|}{ Pro-apoptotic } \\
\hline Casp3 & $1.00 \pm 0.07$ & $1.19 \pm 0.07$ & $1.12 \pm 0.09$ & $1.16 \pm 0.09$ & $1.15 \pm 0.07$ & $1.30 \pm 0.08$ & NS & NS & NS \\
\hline P53 & $1.00 \pm 0.18$ & $0.78 \pm 0.17$ & $1.05 \pm 0.12$ & $0.62 \pm 0.10$ & $0.90 \pm 0.13$ & $0.70 \pm 1.28$ & NS & NS & NS \\
\hline HSP70 & $1.00 \pm 0.10$ & $1.50 \pm 0.13$ & $1.00 \pm 0.05$ & $1.32 \pm 0.11$ & $1.39 \pm 0.13$ & $1.37 \pm 0.09$ & $<0.01$ & NS & NS \\
\hline Bax:Bcl2 & $0.88 \pm 0.16$ & $0.76 \pm 0.32$ & $0.38 \pm 0.10$ & $0.50 \pm 0.41$ & $0.45 \pm 0.10$ & $0.46 \pm 0.08$ & NS & NS & NS \\
\hline$T G F \beta 1$ & $1.00 \pm 0.19$ & $1.50 \pm 0.18$ & $1.18 \pm 0.16$ & $1.47 \pm 0.15$ & $1.48 \pm 0.19$ & $0.79 \pm 0.20$ & NS & NS & $<0.01$ \\
\hline
\end{tabular}

All data are expressed relative to the c-section control group. Values are mean \pm SEM; $n=6-9$ /group. Statistical analysis, 2-way ANOVA with the 2 independent variables as birth mode $\left(P_{\text {Birth }}\right.$; control c-section vs intrapartum asphyxia) and drug administration $\left(P_{\text {Treat }}\right.$ saline, wtAPC, or 3K3A-APC).

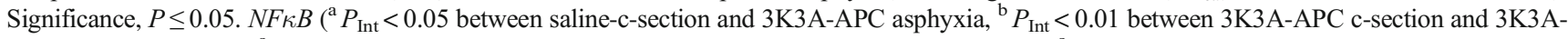
APC asphyxia); $T N F \alpha$ ( ${ }^{\mathrm{a}} P_{\mathrm{Int}}<0.01$ between $3 \mathrm{~K} 3 \mathrm{~A}-\mathrm{APC} \mathrm{c}$-section and $3 \mathrm{~K} 3 \mathrm{~A}-\mathrm{APC}$ asphyxia); $I L-6$ ( ${ }^{\mathrm{a}} P_{\text {Int }}<0.05$ between saline-asphyxia and wtAPC asphyxia, ${ }^{\mathrm{b}} P_{\mathrm{Int}}<0.05$ between wtAPC asphyxia and $3 \mathrm{~K} 3 \mathrm{~A}-\mathrm{APC}$ asphyxia); $I L-4$ ( ${ }^{\mathrm{a}} P_{\mathrm{Int}}<0.01$ between saline-asphyxia and $3 \mathrm{~K} 3 \mathrm{~A}-\mathrm{APC} \mathrm{c}-\mathrm{section},{ }^{\mathrm{b}} P_{\mathrm{Int}}$ $<0.05$ between $3 \mathrm{~K} 3 \mathrm{~A}-\mathrm{APC}$ c-section and 3K3A-APC asphyxia)

Table 4 DGM RT-qPCR analysis

\begin{tabular}{|c|c|c|c|c|c|c|c|c|c|}
\hline & \multicolumn{2}{|l|}{ Saline } & \multicolumn{2}{|l|}{ wtAPC } & \multicolumn{2}{|l|}{ 3K3A-APC } & \multicolumn{3}{|c|}{ Statistics } \\
\hline & C-section & Asphyxia & C-section & Asphyxia & C-section & Asphyxia & $P_{\text {Birth }}$ & $P_{\text {Treat }}$ & $P_{\text {Int }}$ \\
\hline \multicolumn{10}{|c|}{ Pro-inflammatory } \\
\hline$N F \kappa B$ & $1.00 \pm 0.09$ & $1.52 \pm 0.16$ & $1.27 \pm 0.16$ & $1.75 \pm 0.26$ & $1.02 \pm 0.13$ & $1.57 \pm 0.08$ & $<0.001$ & NS & NS \\
\hline$T N F \alpha$ & $1.00 \pm 0.06$ & $1.06 \pm 0.13$ & $1.57 \pm 0.28$ & $1.18 \pm 0.24$ & $1.18 \pm 0.05$ & $1.36 \pm 0.20$ & NS & NS & NS \\
\hline$I L-6$ & $1.00 \pm 0.18$ & $0.86 \pm 0.10$ & $1.03 \pm 0.08$ & $0.77 \pm 0.10$ & $0.85 \pm 0.10$ & $1.17 \pm 0.25$ & NS & NS & NS \\
\hline$I L-1 \beta$ & $1.00 \pm 0.04$ & $1.07 \pm 0.15$ & $0.96 \pm 0.06$ & $0.78 \pm 0.09$ & $0.86 \pm 0.06$ & $0.83 \pm 0.09$ & NS & NS & NS \\
\hline \multicolumn{10}{|c|}{ Neuronal population markers } \\
\hline$S 100 B$ & $1.00 \pm 0.11$ & $1.24 \pm 0.06$ & $0.83 \pm 0.21$ & $1.27 \pm 0.21$ & $1.25 \pm 0.04$ & $1.23 \pm 0.29$ & NS & NS & NS \\
\hline ENO2 & $1.00 \pm 0.26$ & $2.14 \pm 0.33$ & $1.34 \pm 0.23$ & $1.45 \pm 0.65$ & $2.05 \pm 0.37$ & $1.56 \pm 0.35$ & NS & NS & NS \\
\hline \multicolumn{10}{|c|}{ Anti-inflammatory } \\
\hline$I L-4$ & $1.00 \pm 0.12$ & $0.90 \pm 0.12$ & $0.90 \pm 0.15$ & $0.94 \pm 0.19$ & $0.63 \pm 0.07$ & $0.67 \pm 0.10$ & NS & NS & NS \\
\hline \multicolumn{10}{|l|}{ Pro-apoptotic } \\
\hline Casp3 & $1.00 \pm 0.08^{\mathrm{a}}$ & $1.03 \pm 0.04^{\mathrm{b}}$ & $0.90 \pm 0.05^{\mathrm{c}}$ & $1.10 \pm 0.09$ & $1.04 \pm 0.06^{\mathrm{d}}$ & $0.53 \pm 0.14^{\mathrm{a}, \mathrm{b}, \mathrm{c}, \mathrm{d}}$ & NS & $<0.05$ & $<0.001$ \\
\hline P53 & $1.00 \pm 0.09$ & $1.61 \pm 0.12$ & $1.06 \pm 0.12$ & $1.46 \pm 0.13$ & $1.57 \pm 0.40$ & $1.59 \pm 0.16$ & $<0.05$ & NS & NS \\
\hline HSP70 & $1.00 \pm 0.07$ & $1.04 \pm 0.06$ & $0.86 \pm 0.13$ & $1.08 \pm 0.08$ & $0.98 \pm 0.10$ & $1.04 \pm 0.07$ & NS & NS & NS \\
\hline Bax:Bcl2 & $1.13 \pm 0.28$ & $0.83 \pm 0.29$ & $1.65 \pm 0.48$ & $1.19 \pm 0.48$ & $1.60 \pm 0.39$ & $0.84 \pm 0.45$ & NS & NS & NS \\
\hline$T G F \beta 1$ & $1.00 \pm 0.24$ & $0.94 \pm 0.13$ & $0.98 \pm 0.24$ & $0.62 \pm 0.18$ & $1.25 \pm 0.23$ & $1.01 \pm 0.10$ & NS & NS & NS \\
\hline
\end{tabular}

All data are expressed relative to c-section control group. Values are mean \pm SEM; $n=6-9 /$ group. Statistical analysis, 2 -way ANOVA with the 2 independent variables as birth mode $\left(P_{\text {Birth }}\right.$; control c-section vs intrapartum asphyxia) and drug administration $\left(P_{\text {Treat }}\right.$ saline, wtAPC, or 3K3A-APC). Significance, $P \leq 0.05$. Casp $3\left({ }^{\mathrm{a}} P_{\mathrm{Int}}<0.01\right.$ between saline-c-section and $3 \mathrm{~K} 3 \mathrm{~A}-\mathrm{APC}$ asphyxia, ${ }^{\mathrm{b}} P_{\mathrm{Int}}<0.001$ between saline-asphyxia and $3 \mathrm{~K} 3 \mathrm{~A}-\mathrm{APC}$ asphyxia, ${ }^{\mathrm{c}} P_{\text {Int }}<0.05$ between wtAPC c-section and $3 \mathrm{~K} 3 \mathrm{~A}-\mathrm{APC}$ asphyxia, ${ }^{\mathrm{d}} P_{\text {Int }}<0.01$ between $3 \mathrm{~K} 3 \mathrm{~A}-\mathrm{APC}$ c-section and $3 \mathrm{~K} 3 \mathrm{~A}-\mathrm{APC}$ asphyxia) 


\section{Neuropathology}

Examination of the H\&E-stained brain sections did not reveal any gross morphological changes (i.e., infarcts, cystic lesions) or evidence of intracerebral hemorrhage in any group (data not shown). Representative images of immunostaining for CD11 $\beta$, GFAP, and TUNEL are shown in Fig. 1, with quantified results shown in Figs. 2, 3, 4, and 5.

Microglia and Macrophages In all 4 brain regions analyzed, there were no significant changes in the number of cells identified by Iba-1-positive after intrapartum asphyxia alone or after treatment with either wtAPC or 3K3A-APC (data not shown). There was a trend for increased numbers of Iba-1positive cells displaying an amoeboid or activated morphology following intrapartum asphyxia in the corpus callosum (Fig. 2A; $P_{\text {Birth }}=0.08$ ) and hippocampus (Fig. 2D; $P_{\text {Birth }}=$ 0.1 ). Administration of either wtAPC or $3 \mathrm{~K} 3 \mathrm{~A}-\mathrm{APC}$ did not alter this outcome. To elucidate this observation further, $\mathrm{CD} 11 \beta$ (as a marker specific for activated microglia) was assessed.

In the corpus callosum, there was a near-significant increase in the number of CD11 $\beta$-positive cells (Fig. 1) in the intrapartum asphyxia-saline group, compared to c-section-
Fig. 1 Representative neuropathology. Immunohistochemistry of CD11 $\beta$ (corpus callosum), GFAP (cortex), and TUNEL (corpus callosum) in c-section-saline (A-C), birthasphyxia-saline (D-F), c-sectionwild-type APC $(\mathrm{G}-\mathrm{I})$, birthasphyxia-wild-type APC (J-L), csection-3K3A-APC (M-O), and birth-asphyxia-3K3A-APC (P-R) treatment groups. Examples of CD11 $\beta$-positive cells are indicated by asterisks, GFAP-positive cells are indicated by open arrows, and TUNEL-positive cells are indicated by circles. Scale bars $=20 \mu \mathrm{m}$ for CD11 $\beta, 20 \mu \mathrm{m}$ for GFAP, and $10 \mu \mathrm{m}$ for TUNEL panels

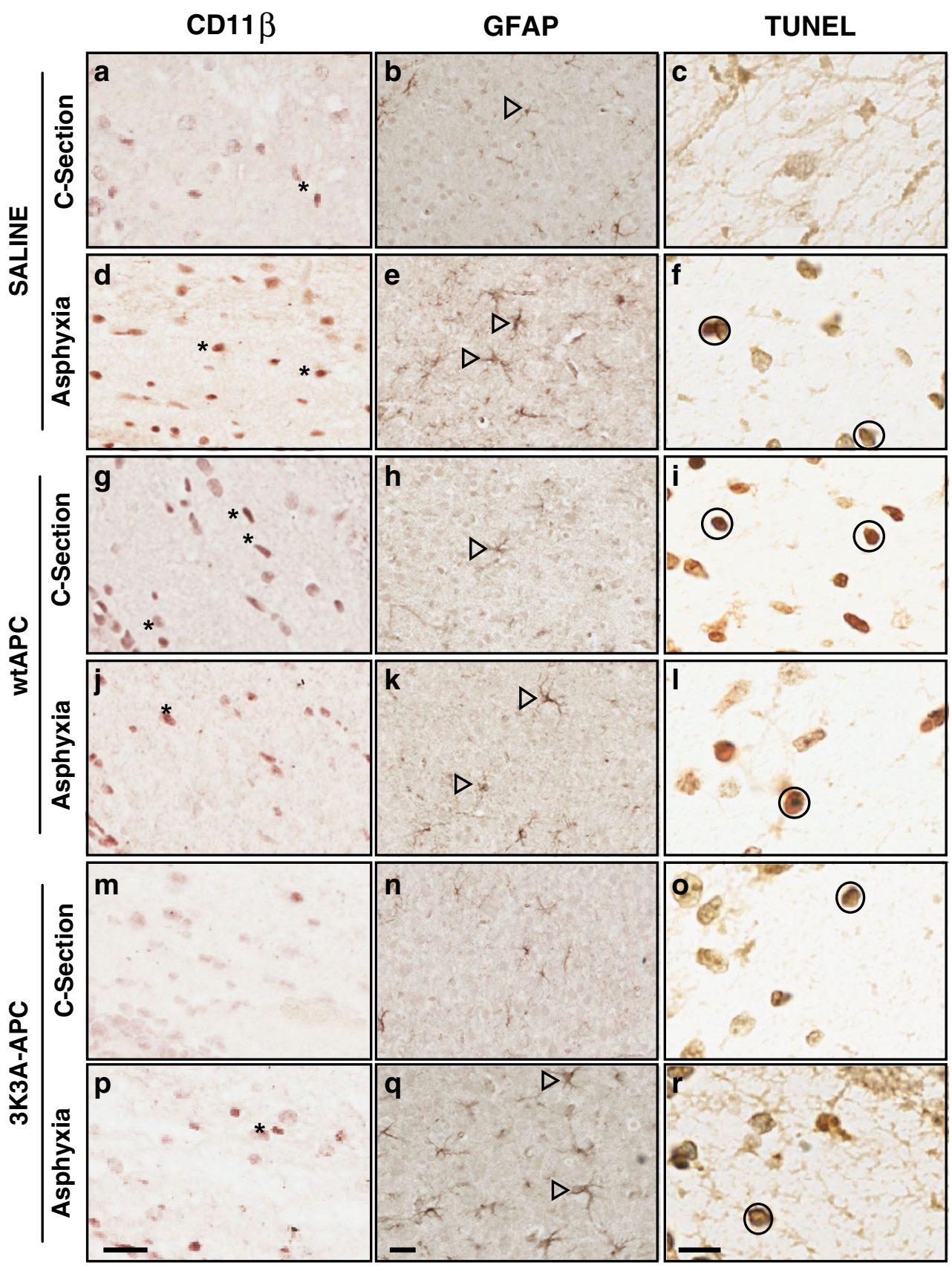


a Iba-1(activated) - Corpus Callosum

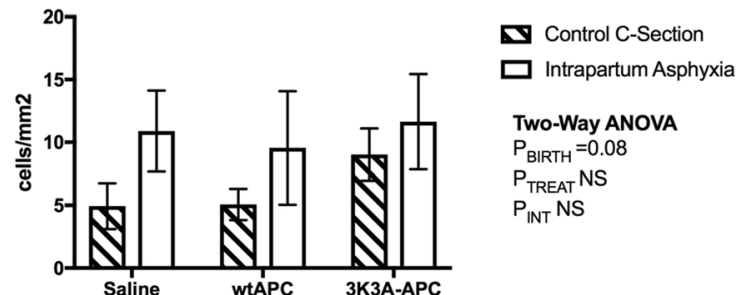

C Iba-1 (activated) - DGM

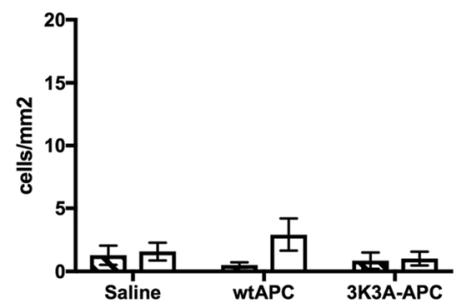

$\boldsymbol{\nabla}$ Control C-Section

$\square$ Intrapartum Asphyxia

Two-Way ANOVA

$\mathrm{P}_{\text {BIRTH }}$ NS

$P_{\text {TREAT }}$ NS

$P_{\text {INT }}$ NS

Fig. 2 Reactive microglial cell immunostaining. Counts of activated Iba1 cells in the corpus callosum (A), cortex (B), deep gray matter (C), and hippocampus (D), at 24-h postnatal age. Values are means \pm SEM; $n=6$ /

saline controls (Fig. 3A; post hoc $P=0.06$ ). 3K3A-APC treatment reduced the number of $\mathrm{CD} 11 \beta$-positive cells in the asphyxiated pups (Fig. $3 \mathrm{~A} ; P_{\text {Treat }}<0.01$ ), whereas treatment of c-section-delivered offspring with wtAPC caused a significant increase in CD11 $\beta$-positive cells when compared to groups treated with $3 \mathrm{~K} 3 \mathrm{~A}-\mathrm{APC}$. Hence, there was a significant interaction between treatment and mode of delivery for CD11 $\beta$ positive cells (Fig. $3 \mathrm{~A} ; P_{\text {Int }}<0.05$ ). In the cortex, intrapartum

a CD11 $\beta$-Corpus Callosum

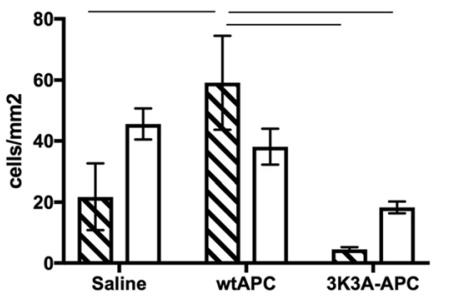

Control C-Section

Intrapartum Asphyxia

Two-Way ANOVA

$\mathrm{P}_{\mathrm{BIRTH}} \mathrm{NS}$

$\mathrm{P}_{\text {TREAT }}<0.01$

$P_{\text {INT }}<0.05$

C

CD11 $\beta$ - DGM

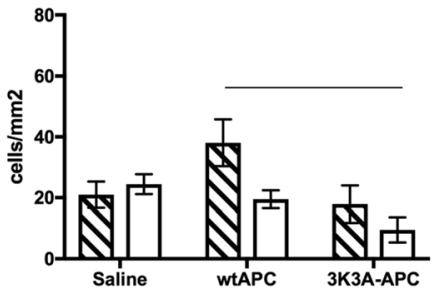

Control C-Section

Intrapartum Asphyxia

Two-Way ANOVA

$\mathrm{P}_{\mathrm{BIRTH}} \mathrm{NS}$

$P_{\text {TREAT }}<0.05$

$\mathrm{P}_{\text {INT }}$ NS

Fig. 3 Macrophage/microglia immunostaining. Counts of CD11 $\beta$ positive staining in the corpus callosum (A), cortex (B), deep grey matter (C) and hippocampus (D), at $24 \mathrm{~h}$ postnatal age. Values are

b Iba-1 (activated) - Cortex

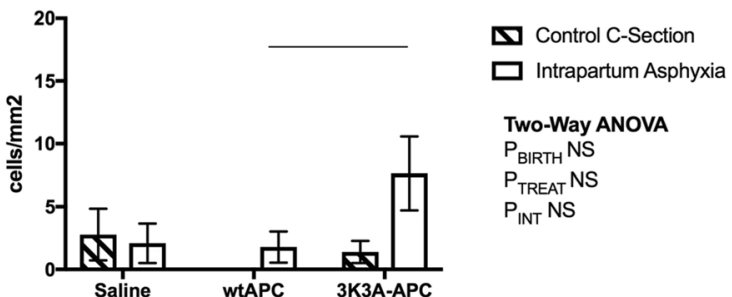

\section{d Iba-1(activated) - Hippocampus}

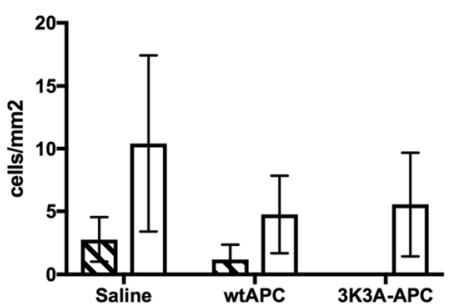

Control C-Section

$\square$ Intrapartum Asphyxia

Two-Way ANOVA

$\mathrm{P}_{\mathrm{BIRTH}}=0.1$

$\mathrm{P}_{\text {TREAT }} \mathrm{NS}$

$P_{\text {INT }}$ NS

group. Statistical analysis, 2 -way ANOVA. Significance, $P \leq 0.05$. Line represents significant differences determined with post hoc analysis

asphyxia increased CD11 $\beta$-positive cells in the saline-treated pups, compared to the c-section-saline controls (Fig. 3B; post hoc $P<0.01)$. Both wtAPC and $3 \mathrm{~K} 3 \mathrm{~A}-\mathrm{APC}$ treatments tended to reduce the $\mathrm{CD} 11 \beta$-positive cells after intrapartum asphyxia, but as observed in the corpus callosum, a significant increase in CD11 $\beta$-positive cells was present in the c-section group treated with wtAPC, compared to the c-section-saline group (Fig. 3B; $P<0.05$ ). Hence, there was a nonsignificant

b

CD11 $\beta$ - Cortex

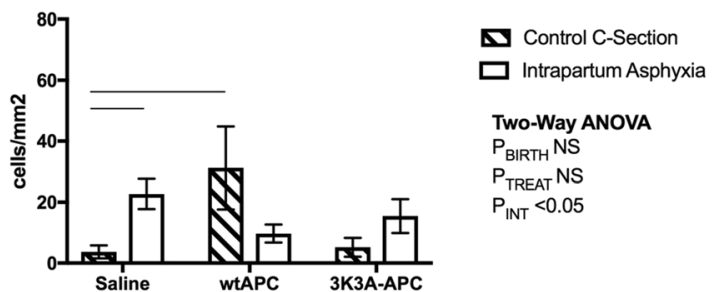

d

CD11 $\beta$ - Hippocampus

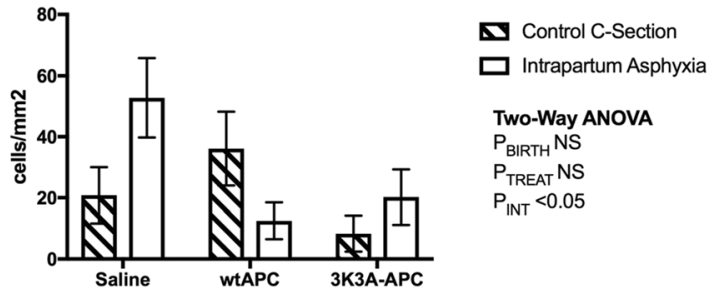

means $\pm \mathrm{SEM} ; n=6 /$ group. Statistical analysis, two-way ANOVA. Significance $P \leq 0.05$. Line represents significant differences determined with post hoc analysis 
a GFAP- Corpus Callosum

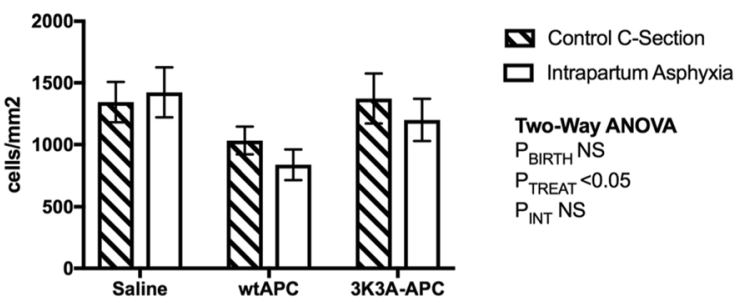

C

GFAP- DGM

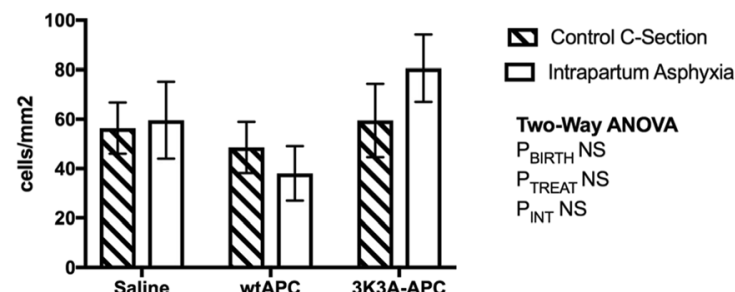

Fig. 4 Astroglial cell immunostaining. Counts of activated GFAPpositive staining in the corpus callosum (A), cortex (B), deep gray matter (C), and hippocampus (D), at 24-h postnatal age. Values are means \pm

effect of intrapartum asphyxia, but a significant interaction between treatment and birth mode (Fig. 3B; $P_{\text {Int }}<0.05$ ). There was no effect of intrapartum asphyxia on the number of CD11 $\beta$-positive cells in the DGM (Fig. 3C), but wtAPC treatment significantly increased the number of these cells following c-section delivery (Fig. 3C; $P_{\text {Treat }}<0.05$ ). 3K3AAPC administration had no impact of $\mathrm{CD} 11 \beta$ counts in this region. In the hippocampus, the number of $\mathrm{CD} 11 \beta$-positive cells was higher after asphyxia in saline-treated pups

a

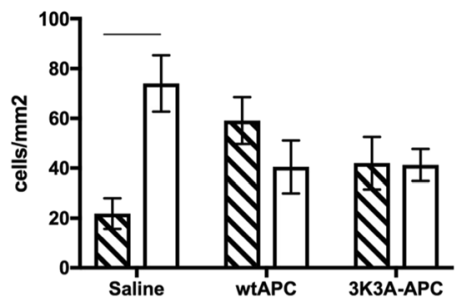

C

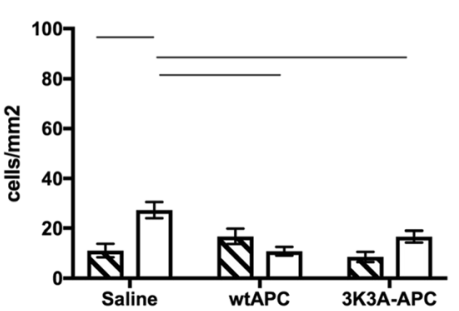

b

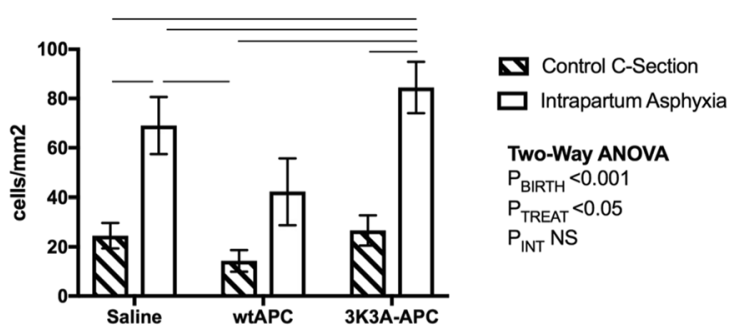

d GFAP- Hippocampus

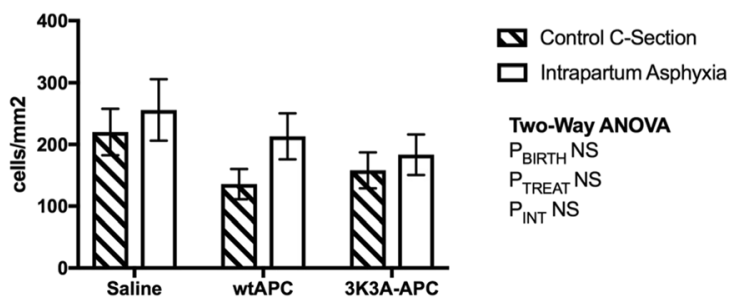

SEM; $n=6$ /group. Statistical analysis, 2-way ANOVA. Significance, $P \leq 0.05$. Line represents significant differences determined with post hoc analysis

compared to the c-section-saline controls; however, this did not reach statistical significance (post hoc $P=0.07$ ). wtAPC decreased CD11 $\beta$-positive cells in the asphyxiated pups but increased CD11 $\beta$-positive cells in the c-section-delivered pups, leading to an interaction between birth mode and treatment in the hippocampus (Fig. 3D; $P_{\text {Int }}<0.05$ ). $3 \mathrm{~K} 3 \mathrm{~A}-\mathrm{APC}$ administration did not alter the number of $\mathrm{CD} 11 \beta$-positive cells in the hippocampus following either c-section or intrapartum asphyxia (Fig. 3D).

b

TUNEL- Cortex

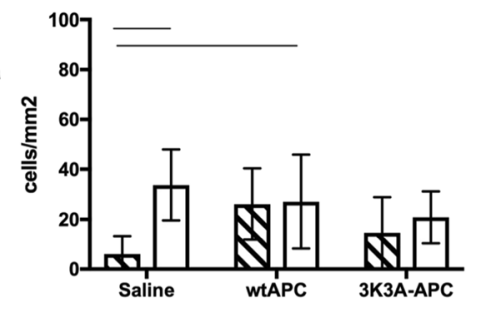

$\boldsymbol{\nabla}$ Control C-Section

$\square$ Intrapartum Asphyxia

$\square$ Intrapartum Asphyxia

Two-Way ANOVA

$\mathrm{P}_{\mathrm{BIRTH}} \mathrm{NS}$

$\mathrm{P}_{\text {TREAT }}$ NS

$P_{\text {INT }}<0.01$

d

(v) Control C-Section

$\square$ Intrapartum Asphyxia

Two-Way ANOVA

$P_{\text {BIRTH }}<0.05$

$P_{\text {TREAT }}<0.05$

$\mathrm{P}_{\text {INT }}<0.01$

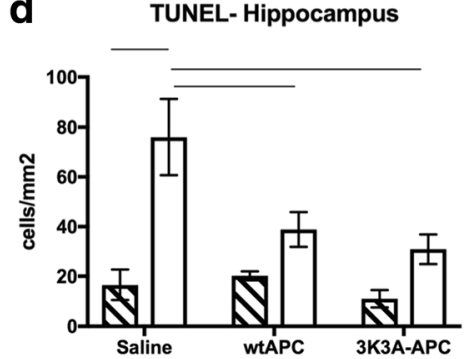

D Control C-Section

$\square$ Intrapartum Asphyxia

Two-Way ANOVA

$P_{\text {BIRTH }}<0.001$

$P_{\text {TREAT }}<0.05$

$\mathrm{P}_{\text {INT }}<0.05$

Fig. 5 Apoptotic cell death. Counts of TUNEL-positive cells in the corpus callosum (A), cortex (B), deep gray matter (C), and hippocampus (D), at 24-h postnatal age. Values are means \pm SEM; $n=6$ /group.

Statistical analysis, 2-way ANOVA. Significance, $P \leq 0.05$. Line represents significant differences determined with post hoc analysis 
Astrocytes The level of GFAP immunoreactivity (Fig. 1) was significantly higher in the corpus callosum and hippocampus compared to the cortex and DGM (Fig. 4). wtAPC administration reduced the number of GFAP-positive cells in the corpus callosum, irrespective of mode of delivery (Fig. 4A; $P_{\text {Treat }}$ $<0.05$ ). In the cortex, increased GFAP was evident at $24 \mathrm{~h}$ after intrapartum asphyxia (Fig. 4B; $P_{\text {Birth }}<0.001$ ), and this was reduced by wtAPC treatment (Fig. 4B; $P_{\text {Treat }}<0.05$ ), but not with 3K3A-APC. There was no effect of mode of birth or $3 \mathrm{~K} 3 \mathrm{~A}-\mathrm{APC}$ treatment on GFAP counts in the DGM or hippocampus (Fig. 4C\&D).

Cell Death In the groups administered saline, intrapartum asphyxia significantly increased the density of dead and dying cells in all 4 brain regions assessed, as indicated by TUNEL immunoreactivity (Figs. 1 and 5). In the corpus callosum, there was a trend for a decreased number of TUNELpositive cells after wtAPC and 3K3A-APC administration to the asphyxiated groups, but this did not reach statistical significance (Fig. 5A; post hoc $P=0.1$ ). A significant increase in TUNEL-positive cells in the c-section pups administered wtAPC also led to a significant interaction between mode of birth and treatment in this region (Fig. $5 \mathrm{~A} ; P_{\text {Int }}<0.01$ ). In the cortex, the number of TUNEL-positive cells in the c-section pups administered wtAPC was also increased compared to the saline administered controls (Fig. 5B; $P_{\text {Birth }}<0.01 ; P_{\text {Int }}<$ $0.05)$. In the DGM and hippocampus, the number of TUNEL-positive cells after intrapartum asphyxia was significantly reduced by both wtAPC and 3K3A-APC, compared to saline treatment (Fig. 5C $\left(P_{\text {Treat }}<0.05, P_{\text {Int }}<0.01\right)$ and Fig. 5D $\left.\left(P_{\text {Treat }}<0.05, P_{\text {Int }}<0.05\right)\right)$.

\section{Discussion}

To our knowledge, this is the first study to evaluate the therapeutic effects of 3K3A-APC in the neonatal brain. Using newborn spiny mice, we investigated the effects of $3 \mathrm{~K} 3 \mathrm{~A}$ APC treatment on gene expression and neuropathology following intrapartum asphyxia and compared the outcomes to treatment with either vehicle (saline) or wtAPC. 3K3A-APC administration at $1 \mathrm{~h}$ after intrapartum asphyxia improved loss of body weight in the first $24 \mathrm{~h}$ after the hypoxic insult. At a gene expression level, 3K3A-APC administration after intrapartum asphyxia decreased mRNA expression of $T G F \beta 1$ in the cerebral cortex and Casp3 mRNA in the DGM but increased $N F \kappa B$ and $T N F \alpha$ mRNA expression in the cortex. Histological analysis showed that $3 \mathrm{~K} 3 \mathrm{~A}-\mathrm{APC}$ administration prevented asphyxia-induced microglial/ macrophage cell aggregation in the corpus callosum and prevented apoptotic cell death in the DGM and hippocampus. While wtAPC reduced the number of TUNEL-positive cells in the cortex of the asphyxiated pups, administration of
wtAPC exacerbated the weight loss over the first $24 \mathrm{~h}$ of life. Notably, wtAPC also led to a marked increase in the number of CD11 $\beta$-positive cells in the 4 brain regions analyzed and increased the number of TUNEL-positive cells in the corpus callosum and cortex of the c-section-delivered pups. These off-target or side effects support findings from other studies that suggest native or wtAPC is inappropriate for administration to neonates [14]. In the current study, the 3K3A-APC variant had more clear-cut protective effects following intrapartum asphyxia.

\section{Neuro-Inflammation and Treatment with 3K3A-APC}

In this model, inflammation was evident in the neonatal brain at $24 \mathrm{~h}$ after the hypoxic insult. Markers of inflammation included increased mRNA expression of the proinflammatory transcription factors $N F \kappa B$ in both the cortex and DGM and $T N F \alpha$ in the cortex; reactive microglia (as indicated by CD11 $\beta$-positive cells) in the corpus callosum, cortex, and hippocampus; and astrogliosis (GFAP-positive cells) in the cortex. These outcomes in the spiny mouse model of intrapartum asphyxia are consistent with a large number of studies of neonatal HI injury, implicating immune cell modulation in neuronal injury and repair mechanisms [31].

3K3A-APC administration prevented reactive microglial (CD11 $\beta$-positive) cell aggregation in the corpus callosum but increased $N F \kappa B$ and $T N F \alpha$ expression levels and astrogliosis in the cortex of the asphyxiated pups $24 \mathrm{~h}$ after the hypoxic ischemic insult. APC is thought to exert antiinflammatory properties through reduction of inflammatory cytokines released from leukocytes and endothelial cells and via downregulation of $N F \kappa B$ expression and activity [7]. Indeed, numerous studies, conducted primarily in adult rodent and cell culture models of stroke and sepsis, have indicated that reducing inflammation is a key feature of APC's cytoprotective properties (see the review of Griffin et al [32]).

We propose that brain maturation, injury progression, and timing of assessment post injury may account for the differences between previous studies and our data presented here, and that the changes we observed after 3K3A-APC administration may not be deleterious. During gestation and in the perinatal period, inflammation can play a role in both normal brain development, injury progression, and neural repair [33]. Studies have shown that recruitment of microglia in the first few hours following injury is a pro-inflammatory response; however, the presence of reactive microglia in the days following an insult is likely a reparative response, as these cells respond to injury by proliferating, upregulating antigen receptors, and invading the area of injury to phagocytose and remove debris [31, 34]. Previous studies have also shown that astrocytes may play a protective role in the neonatal brain following injury. Reactive astrogliosis in response to cerebral injury is critical to scar formation, and it is thought to function 
to i) reduce the spread and persistence of inflammatory cells, ii) aid in repair of the blood-brain barrier, iii) decrease tissue damage and lesion size, and iv) decrease neuronal loss and demyelination [35]. Reactive astrogliosis was observed in a mouse model of infection-induced neonatal white matter injury and in human neonatal tissue. In this study, astrocytes appeared to prevent TGF $\beta 1$ production by microglial cells, which, in turn, inhibited oligodendrocyte maturation and reduced damage [36]. It is interesting to note that in our current study, 3K3A-APC also reduced TGF $\beta 1$ mRNA expression in the cortex. Thus, the ongoing changes in the neonatal spiny mouse brain after the intrapartum asphyxia and 3K3A-APC administration may account for the different responses in inflammatory markers observed in our study, compared to previous in vitro studies of APC [37, 38].

The timing of injury assessment post asphyxia may also be relevant. In the current study, the level of GFAP staining in the cortex was reduced by wtAPC, but not 3K3A-APC treatment. Previous studies by Hutton et al [17] using this spiny mouse model of intrapartum asphyxia also reported increases in astrogliosis (GFAP-positive cells) with increases in expression in the corpus callosum becoming evident $24 \mathrm{~h}$ after insult, but with no significant increase in the hippocampus until 7 days post HI insult. This suggests longer-term assessment of neuroinflammation in this spiny mouse model of intrapartum asphyxia may be needed to provide a more complete picture of the capacity of 3K3A-APC to modulate inflammation-driven neonatal HIE brain injury and repair.

\section{K3A-APC to Prevent Neuronal Apoptotic Cell Death Following Intrapartum Asphyxia}

Both the intrinsic and extrinsic cell death pathways (i.e., mitochondrial membrane-mediated and death receptor-mediated apoptosis) have been implicated in intrapartum asphyxia and neonatal $\mathrm{HI}$ brain injury [39]. At $24 \mathrm{~h}$ after insult, induction of apoptotic/necrotic cell death pathways was evident in the spiny mouse model of intrapartum asphyxia, with increased HSP70 mRNA expression in the cortex, p53 mRNA expression in the DGM, and marked increases in TUNEL-positive cells within all of the 4 brain regions analyzed with the most pronounced changes in the corpus callosum and hippocampus. This finding is consistent with other clinical studies that central and subcortical regions (i.e., corpus callosum) tend to show greater loss of white matter with HIE [3]. Previous studies of intrapartum asphyxia in spiny mice have also shown increased apoptosis in the hippocampus (CA1, CA2, CA3, dentate gyrus) as well as the corpus callosum, which may contribute to the functional deficits in nonspatial and taskassociated memory, and motor impairments, suggesting the sensory and motor cortex are also affected in this model of intrapartum asphyxia [17].
APC has been previously shown to downregulate the intrinsic apoptotic pathway through suppression of proapoptotic proteins Bax and P53 [8]. Furthermore, APC upregulates the expression of antiapoptotic proteins such as Bcl2 [40], preventing pore formation in the mitochondrial membrane through inhibition of pro-apoptotic proteins [41]. In the current study, 3K3A-APC administration ameliorated the increase in $T G F \beta 1$ mRNA expression in the cortex and reduced Casp 3 mRNA expression in the DGM of the asphyxiated pups; however, there was no impact of asphyxia or of the wtAPC or $3 \mathrm{~K} 3 \mathrm{~A}-\mathrm{APC}$ treatments on the Bax/Bcl2 mRNA ratio. Increased Bax protein expression at $24 \mathrm{~h}$ post intrapartum asphyxia has been reported in the cortical subplate, thalamus, and piriform cortex of the spiny mouse, suggesting assessment of translational changes rather than mRNA might be more appropriate after $24 \mathrm{~h}$ of injury progression [18]. Importantly, both 3K3A-APC and wtAPC reduced the number of TUNEL-positive cells in the DGM and hippocampus. Notably, 3K3A-APC administration at $1 \mathrm{~h}$ after resuscitation from intrapartum asphyxia also improved loss of body weight in the first $24 \mathrm{~h}$ after the hypoxic insult, which is likely to be secondary to reduced feeding and therefore reflects the general well-being of the newborn spiny mice. The amelioration of cell death by $3 \mathrm{~K} 3 \mathrm{~A}-\mathrm{APC}$ administration is consistent with previous studies of APC focused on neonatal brain injury $[12,13]$.

\section{Potential Adverse Effects of wtAPC Administration to Uninjured Offspring}

In the asphyxiated pups, while wtAPC reduced TUNELpositive cells in the DGM and hippocampus, and CD11 $\beta$ positive cells in the cortex and hippocampus, administration of wtAPC exacerbated the weight loss over the first $24 \mathrm{~h}$ of life. Treatment of control pups with wtAPC also had the adverse effects, with increased numbers of $C D 11 \beta$-positive cells in all 4 brain regions analyzed, as well as increased TUNELpositive cells in the corpus callosum and cortex. These findings suggest a pro-inflammatory effect with increased cell death in the uninjured brain and add to the concerns about the use of wtAPC in neonates [14].

It should be noted that previous rodent studies investigating the benefits of APC for either perinatal ischemic/reperfusion brain injury or adult ischemic stroke (reviewed by Isobe et al [42]) have not routinely included a no-injury group treated with APC in its native form, as we have done here. We are therefore unable to comment on whether the adverse outcomes reported in the c-section cohort of the current study are specific to the newborn spiny mouse brain and the growth and maturation that occur at this time, or whether wtAPC actually leads to inflammation and cell death in the uninjured perinatal brain. Nevertheless, this observation is important because it indicates the potential for APC in its native form 
to compromise the developing brain. APC's ability to mitigate increases in NO production that occur during ischemia/ reperfusion is 1 proposed mode of neuroprotection following injury [43]. However, it is possible that suppression of NO in the absence of injury could alter vascular tone and oxygen availability leading to ROS production and cell death in otherwise normal tissue. Such negative impacts of altered NO production in the absence of injury have been reported in rodent studies of antioxidant treatment using vitamin $\mathrm{C}$ [44-46]. As in the current study, these studies did include a no-injury group and reported vascular endothelial dysfunction later in life in offspring exposed to vitamin $\mathrm{C}$ in the absence of hypoxia [44-46]. Interestingly, wtAPC decreased astrogliosis in the corpus callosum and cortex irrespective of the mode of birth, despite the effect it had of increasing CD11 $\beta$-positive and TUNEL-positive cell counts in the c-section controls. The reduction of GFAP by wtAPC in the presence of increased inflammatory cells and cell death raises the possibility that an important neural repair process may have been disrupted. These studies together with our results highlight the need to include appropriate control groups in preclinical animal studies.

\section{Strengths and Limitations}

This study used the precocial spiny mouse to study the effects of intrapartum asphyxia on the brain [17-22]. The spiny mouse differs from conventional laboratory rodents (mice, rats) in that considerable brain maturation (including the beginnings of myelination) occurs in utero before birth [47]; hence, acute hypoxia delivered during the intrapartum period can be used as a model of oxygen starvation that occurs at birth in some human pregnancies. This study also directly compared the therapeutic potential of both wtAPC and $3 \mathrm{~K} 3 \mathrm{~A}-\mathrm{APC}$ within the same cohort of animals.

A limitation of the study is that observations were made at only 1 time point ( $24 \mathrm{~h}$ ) after the $\mathrm{HI}$ insult at birth. While this was an opportune time to assess neuropathology in our model, it was potentially too late to thoroughly investigate changes in cytokine mRNA expression definitively. This may have contributed to some of the differences in $N F \kappa B$ expression observed in this study compared to previously published studies on adult stroke. It is well known that HI brain damage evolves over many hours and days in human neonates, and the socalled "secondary" and "tertiary" phases of brain damage contribute substantially to the long-term neurodevelopmental deficits. Therefore, the full impact of either wtAPC or 3K3A$\mathrm{APC}$ on the perinatal brain remains to be investigated.

\section{Conclusion}

Immunomodulation and apoptotic/necrotic cell death are mechanisms associated with the pathophysiology of neonatal hypoxic ischemic encephalopathy. In this spiny mouse model of intrapartum asphyxia, 3K3A-APC has a therapeutic potential in ameliorating cell death, without inducing any adverse effects, whereas the native or wild-type APC is less effective and has some untoward effects in the undamaged neonatal brain. 3K3A-APC should therefore be investigated further as a potentially useful drug to ameliorate damage to the neonatal brain following intrapartum asphyxia.

Acknowledgments The authors would like to thank ZZ Biotech LLC (a biotechnology company with a mission to develop APC and its functional mutants for the treatment of stroke and other neurological disorders) for providing the $3 \mathrm{~K} 3 \mathrm{~A}-\mathrm{APC}$ used in this study. We also thank Ms. Mina Khalaji for her technical assistance in the laboratory, and the Hudson Institute of Medical Research's Genomics and Histology Platforms. This work was supported by the Victorian Government's Operational Infrastructure Support Program to the Hudson Institute of Medical Research and by the Phyllis Connor Memorial Trust. During these studies, SJE was supported by an NHMRC Early Career Fellowship; HD was supported by an NHMRC Career Development Fellowship; DWW was a senior scientist at The Ritchie Centre at the time of this study and is now a program leader in Neurodevelopment in Health and Disease (NDHD) at RMIT University, Melbourne; and FYW is supported by the NHMRC/ Cerebral Palsy Alliance Career Development Fellowship.

Required Author Forms Disclosure forms provided by the authors are available with the online version of this article.

\section{References}

1. Padayachee N, Ballot DE. Outcomes of neonates with perinatal asphyxia at a tertiary academic hospital in Johannesburg. S Afri J Child Health 2013;7(3):89-94.

2. Jacinto SJ, Gieron-Korthals M, Ferreira JA. Predicting outcome in hypoxic-ischemic brain injury. Pediatr Clin N Am 2001;48(3):647660 .

3. Volpe JJ. Neonatal encephalopathy: an inadequate term for hypoxic-ischemic encephalopathy. Ann Neurol 2012;72(2):156-166.

4. Zlokovic BV, Griffin JH. Cytoprotective protein C pathways and implications for stroke and neurological disorders. Trends Neurosci 2011;34(4):198-209.

5. Mosnier LO, Zlokovic BV, Griffin JH. Cytoprotective-selective activated protein $\mathrm{C}$ therapy for ischaemic stroke. Thromb Haemost 2014;112(5):883-892.

6. Gabre $\mathrm{J}$, et al. Activated protein $\mathrm{C}$ accelerates venous thrombus resolution through heme oxygenase-1 induction. J Thromb Haemost 2014;12(1):93-102.

7. Esmon CT. Protein C anticoagulant system - anti-inflammatory effects. In: Seminars in immunopathology. Springer, 2012.

8. Meek DW. The p53 response to DNA damage. DNA Repair 2004;3(8):1049-1056.

9. Riewald M, et al. Activation of endothelial cell protease activated receptor 1 by the protein C pathway. Science 2002;296(5574): 1880-1882.

10. Cheng T, et al. Activated protein C blocks p53-mediated apoptosis in ischemic human brain endothelium and is neuroprotective. Nat Med 2003;9(3):338-342.

11. Joyce DE, et al. Gene expression profile of antithrombotic protein $\mathrm{C}$ defines new mechanisms modulating inflammation and apoptosis. $\mathrm{J}$ Biol Chem 2001;276(14):11199-11203. 
12. Yesilirmak DC, et al. Effects of activated protein $\mathrm{C}$ on neonatal hypoxic ischemic brain injury. Brain Res 2008;1210:56-62.

13. Eliwan $\mathrm{H}$, et al. Neonatal brain injury and systemic inflammation: modulation by activated protein $\mathrm{C}$ ex vivo. Clin Exp Immunol 2015;179(3):477-484.

14. Nadel S, et al. Drotrecogin alfa (activated) in children with severe sepsis: a multicentre phase III randomised controlled trial. Lancet 2007;369(9564):836-843.

15. Williams PD, et al. Preclinical safety and pharmacokinetic profile of 3K3A-APC, a novel, modified activated protein $\mathrm{C}$ for ischemic stroke. Curr Pharm Des, 2012;18(27):4215-4222.

16. Wang Y, et al. Differential neuroprotection and risk for bleeding from activated protein $\mathrm{C}$ with varying degrees of anticoagulant activity. Stroke 2009;40(5):1864-1869.

17. Hutton L, et al. Neuroprotective Properties of Melatonin in a Model of Birth Asphyxia in the Spiny Mouse (Acomys cahirinus). Dev Neurosci 2009;31(5):437-451.

18. Ireland $\mathrm{Z}$, et al. A maternal diet supplemented with creatine from mid-pregnancy protects the newborn spiny mouse brain from birth hypoxia. Neuroscience 2011;194:372-79.

19. Ellery SJ, et al. Creatine pretreatment prevents birth asphyxiainduced injury of the newborn spiny mouse kidney. Pediatr Res 2012;73(2):201-208.

20. Ellery SJ, et al. Renal dysfunction in early adulthood following birth asphyxia in male spiny mice, and its amelioration by maternal creatine supplementation during pregnancy. Pediatr Res 2016;81(4):646-653.

21. LaRosa DA, et al. Maternal creatine supplementation during pregnancy prevents long-term changes in diaphragm muscle structure and function after birth asphyxia. PLoS One 2016;11(3):e0149840.

22. LaRosa DA, et al. Maternal creatine supplementation during pregnancy prevents acute and long-term deficits in skeletal muscle after birth asphyxia: a study of structure and function of hind limb muscle in the spiny mouse. Pediatr Res, 2016;80(6):852-860.

23. Dickinson H, Walker D. Managing a colony of spiny mice (Acomys cahirinus) for perinatal research. In: Australian and New Zealand Council for the Care of Animals in Research and Training (ANZCCART) News. 2007;20(1)4-11.

24. Lyden $P$, et al. Phase 1 safety, tolerability and pharmacokinetics of 3K3A-APC in healthy adult volunteers. Curr Pharm Des 2013;19(42):7479-7485.

25. Reagan-Shaw S, Nihal M, Ahmad N. Dose translation from animal to human studies revisited. FASEB J 2008. 22(3):659-661.

26. Vandesompele J, et al. Accurate normalization of real-time quantitative RT-PCR data by geometric averaging of multiple internal control genes. Genome Biol 2002;3(7):31-34.

27. Paxinos G, Halliday G, Watson C, Koutcherov Y, Wang H. Atlas of the developing mouse brain: At E17.5, PO, and P6. Academic Press, San Diego, 2007.

28. Hutton LC, Castillo-Melendez M, Walker DW. Uteroplacental inflammation results in blood brain barrier breakdown, increased activated caspase 3 and lipid peroxidation in the late gestation ovine fetal cerebellum. Dev Neurosci 2007;29(4-5):341-354.
29. Karperien A, Ahammer H, Jelinek HF. Quantitating the subtleties of microglial morphology with fractal analysis. Front Cell Neurosci 2013;7:3.

30. Fox J. Applied regression analysis and generalized linear models. Sage Publications, Thousand Oaks, 2015.

31. Liu F, Mccullough LD. Inflammatory responses in hypoxic ischemic encephalopathy. Acta Pharmacol Sin 2013;34(9):1121.

32. Griffin JH, Zlokovic BV, Mosnier LO. Activated protein C, protease activated receptor 1 and neuroprotection. Blood 2018. p. blood2018-02-769026.

33. Hagberg $\mathrm{H}$, et al. The role of inflammation in perinatal brain injury. Nat Rev Neurol 2015;11(4):192.

34. McRae A, et al. Microglia activation after neonatal hypoxic-ischemia. Dev Brain Res 1995;84(2):245-252.

35. Sofroniew MV. Molecular dissection of reactive astrogliosis and glial scar formation. Trends Neurosci 2009;32(12):638-647.

36. Nobuta $\mathrm{H}$, et al. STAT3-Mediated astrogliosis protects myelin development in neonatal brain injury. Ann Neurol 2012;72(5):750 765.

37. Joyce DE, et al. Gene expression profile of antithrombotic protein $\mathrm{C}$ defines new mechanisms modulating inflammation and apoptosis. $\mathrm{J}$ Biol Chem 2001;276:11199-11203.

38. Riewald M, Ruf W. Protease-activated receptor-1 signaling by activated protein $\mathrm{C}$ in cytokine-perturbed endothelial cells is distinct from thrombin signaling. J Biol Chem 2005;280(20):19808-19814.

39. Hernández-Jiménez M, et al. Apoptosis-related proteins are potential markers of neonatal hypoxic-ischemic encephalopathy (HIE) injury. Neurosci Lett 2014;558:143-148.

40. Sakar A, et al. Effect of recombinant human activated protein $\mathrm{C}$ on apoptosis-related proteins. Eur J Histochem 2007;51(2):103.

41. Salakou $\mathrm{S}$, et al. Increased $\mathrm{Bax} / \mathrm{Bcl}-2$ ratio up-regulates caspase-3 and increases apoptosis in the thymus of patients with myasthenia gravis. In Vivo, 2007;21(1):123-132.

42. Griffin $\mathrm{JH}$, et al. Activated protein $\mathrm{C}$ promotes neuroprotection: mechanisms and translation to the clinic. Thromb Res 2016;141: S62-S64.

43. Isobe $\mathrm{H}$, et al. Activated protein $\mathrm{C}$ prevents endotoxin-induced hypotension in rats by inhibiting excessive production of nitric oxide. Circulation 2001;104(10):1171-1175.

44. Giussani DA, et al. Developmental programming of cardiovascular dysfunction by prenatal hypoxia and oxidative stress. PLoS One 2012;7(2):e31017.

45. Kane $\mathrm{AD}$, et al. Vitamin $\mathrm{C}$ prevents intrauterine programming of in vivo cardiovascular dysfunction in the rat. Circ J 2013;77(10): 2604-2611.

46. Herrera EA, et al. Antioxidant treatment alters peripheral vascular dysfunction induced by postnatal glucocorticoid therapy in rats. PLoS One 2010;5(2): p. e9250.

47. Brunjes P. A comparative study of prenatal development in the olfactory bulb, neocortex and hippocampal region of the precocial mouse (Acomys cahirinus) and rat. Dev Brain Res 1989;49(1): p. 7-25. 